Abstracta Iranica

Revue bibliographique pour le domaine irano-aryen

Volume 32-33 | 2013

Comptes rendus des publications de 2009-2010

\title{
Touraj Atabaki (ed.). Iran in the 20th Century. Historiography and Political Culture
}

\section{Clément Therme}

\section{Q OpenEdition}

1 Journals

Édition électronique

URL : http://journals.openedition.org/abstractairanica/40758

DOI : 10.4000/abstractairanica.40758

ISSN : 1961-960X

\section{Éditeur :}

CNRS (UMR 7528 Mondes iraniens et indiens), Éditions de l'IFRI

\section{Édition imprimée}

Date de publication : 1 décembre 2013

ISSN : 0240-8910

\section{Référence électronique}

Clément Therme, "Touraj Atabaki (ed.). Iran in the 20th Century. Historiography and Political Culture », Abstracta Iranica [En ligne], Volume 32-33 | 2013, document 286, mis en ligne le 01 juillet 2016,

consulté le 01 octobre 2020. URL : http://journals.openedition.org/abstractairanica/40758 ; DOI : https://doi.org/10.4000/abstractairanica.40758

Ce document a été généré automatiquement le 1 octobre 2020.

Tous droits réservés 


\title{
Touraj Atabaki (ed.). Iran in the 20th Century. Historiography and Political Culture
}

\author{
Clément Therme
}

\section{RÉFÉRENCE}

Touraj Atabaki (ed.). Iran in the 20th Century. Historiography and Political Culture. London/ New York, I.B. Tauris, 2009, $336 \mathrm{p}$.

1 Cet ouvrage collectif sur l'historiographie de l'Iran au XXe s. vient combler un vide. En effet, chacun des changements politiques radicaux qu'a connus l'Iran au cours du siècle dernier avec notamment deux révolutions (1905-1909 et 1978-1982) s'est traduit par l'émergence de nouvelles perceptions de l'historiographie du pays. Il était donc nécessaire de clarifier ces ruptures et d'apporter un nouvel éclairage sur les développements « erratiques » (p. 3) de la recherche historique en Iran. Le directeur de l'ouvrage, T. Atabaki relève avec justesse que « l'amnésie et la récupération sélective du passé se construisent en fonction de puissants critères idéologiques qu'il s'agisse de la période monarchique ou du gouvernement de la République islamique » (p. 3-4). Dans cette perspective, l'historiographie n'est qu'un outil de reconstruction, par les dirigeants, d'une vision du passé permettant de déterminer les attentes vis-à-vis de l'avenir. Cet ouvrage est le résultat d'une conférence organisée à l'université d'oxford sur les liens entre historiographie et culture politique en Iran au $\mathrm{XX}^{\mathrm{e}}$ siècle. Le tour de force que réussissent le directeur de la publication ainsi que les auteurs des contributions est d'offrir au lecteur une lecture plurielle de l'historiographie de l'Iran au travers de l'ensemble de ses dimensions idéologiques : islamiste, nationaliste, marxiste, complotiste (vision fondée sur les théories du complot) et, enfin, celle centrée sur le genre.

2 Liste des articles: 
3 1- Touraj Atabaki : « Historiography of Twentieth Century Iran: Memory, Amnesia and Invention »

2- Mohamad Tavakoli-Targhi : «Historiography and Crafting Iranian National Identity »

5 3- Abbas Amanat: "Memory and Amnesia in the Historiography of the Constitutional Revolution »

6 4- Oliver Bast: «Disintegrating the 'Discourse of Disintegration': Some Reflections on the Historiography of the Late Qajar Period and Iranian Cultural Memory »

7 5- Touraj Atabaki : « Agency and Subjectivity in Iranian National Historiography » 6- Afshin Marashi : "The Nation's Poet: Ferdowsi and the Iranian National Imagination »

9 7- Kaveh Bayat: «The Pahlavi School of Historiography on the Pahlavi Era »

10 8- Kamran Safamanesh : « Architectural Historiography 1921-1942 »

11 9- Houchang E. Chehabi : 'The Paranoid Style in Iranian Historiography »

12 10- Mana Kia, Afsaneh Najmabadi and Sima Shakhsari : « Women, Gender, and Sexuality in Historiography of Modern Iran »

13 11- Afshin Matin-asgari : "Marxism, Historiography and Historical Consciousness in Modern Iran: A Preliminary Study »

14 12- Kamran Scot Aghaie : « Islamist Historiography in Post-Revolutionary Iran ».

\section{AUTEURS}

\section{CLÉMENT THERME}

Paris 